\title{
DETERMINATION OF BLOOD FIBRINOLYTIC ACTIVITY BY MEANS OF GEL FILTRATION IN SEVERAL SKIN DISEASES
}

\author{
KAZUYA YAMAMOTO, AKIKAZU TAKADA* \\ and HITOSHI HATANO** \\ Department of Dermatology, School of Medicine, \\ Keio University, Tokyo
}

(Received for publication December 21, 1964)

\begin{abstract}
Changes of blood fibrinolytic enzyme system in several skin diseases and in experimental dermatitis have been reported by many investigators $(1,2,3,4,5)$. A number of attempts in the isolation, purification, and characterization of human fibrinolytic enzyme system have recently been performed $(6,7,8,9)$. The report of Flodin and Killander(10) with regard to a successful chromatographic method for the human serum proteins has indicated that this procedure seemed to be of value as a compliment to other measuring methods of fibrinolytic activity. According to their principle human sera were fractionated by gel filtration in a new type of dextran gel, Sephadex G-200. The Sephadex gels act as molecular sieves allowing separation of protein or other mixtures and estimation of molecular size. In this paper fractionations of human serum proteins by gel filtration and determinations of fibrinolytic activity in each fractions are reported.
\end{abstract}

\section{MATERIALS AND METHODS}

Human serum: Venous blood from patients with skin diseases and other normal adults was obtained from the antecubital vein. The blood was allowed to clot spontaneously and the serum was separated after centrifugation.

Gel filtration method: Gel filtration was performed by the method of Flodin and Killander(10) principally. Sephadex G-200 (A.B. Pharmacia) was dissolved in an excess of $0.1 \mathrm{M}$ Tris- $\mathrm{HCl}$ (pH8.0) in $0.2 \mathrm{M} \mathrm{NaCl}$ buffer. A column with an inner diameter of $20 \mathrm{~mm}$ was filled with the Sephadex suspension to a height of $300 \mathrm{~mm}$. One $\mathrm{ml}$ of serum was diluted with two $\mathrm{ml}$ of Tris buffer, and one $\mathrm{ml}$ of diluted serum was used for the experiment. Eluent consisted of Tris buffer, and elution was performed with a pressure of $5-10 \mathrm{~cm} \mathrm{Hg}$. The effluent was

* Department of Physiology.

** Professor of Dermatology. 
collected in $5 \mathrm{ml}$ portions in an automatic fraction collector. The procedure was done at $4^{\circ} \mathrm{C}$.

Determination of protein concentration: Protein concentration of the fractions was determined by a modified Folin method(11).

Determination of fibrinolytic activity: After activation of fibrinolytic enzyme system in the fractions with streptokinase, the fibrinolytic activity was estimated by the fibrin plate $\operatorname{method}^{(5)}$.

\section{RESULTS AND DISCUSSION}

Controls: Four normal adults (2 males and 2 females) were selected as controls for the experiments. The typical patterns of normal protein distribution and of normal fibrinolytic activity were showed in Fig. 1. The diluted serum

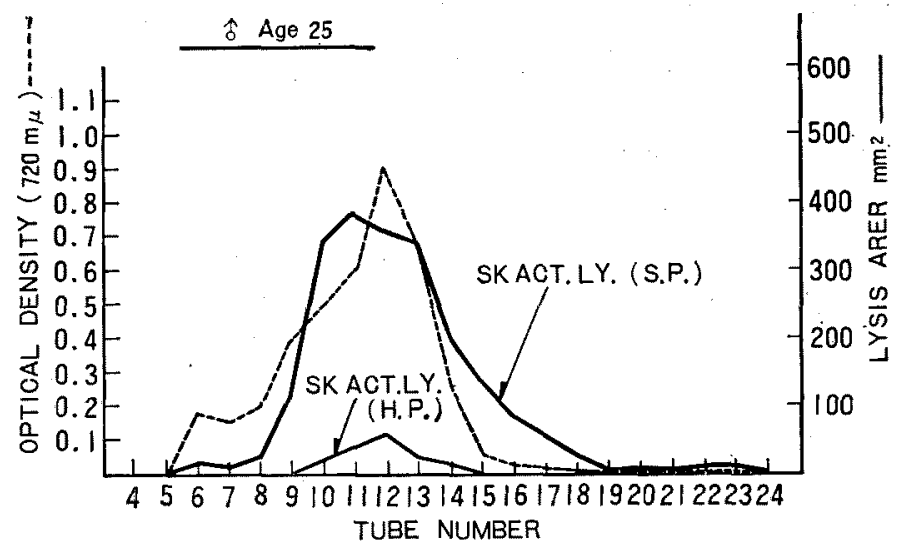

Fig. 1 Normal pattern of protein concentration and of fibrinolytic activity.

SK ACT. LY. (S.P.): streptokinase-activated lysis on a standard plate. SK ACT. LY. (H.P.): streptokinase-activated lysis on a heated plate.

of a 25-year-old male was fractionated. Since the effluent revealed no fibrinolytic activity on a standard fibrin plate, $0.1 \mathrm{ml}$ of the solution, containing 50 units of streptokinase, was added to $0.9 \mathrm{ml}$ of the effluent, and the mixture was incubated for $10 \mathrm{~min}$. at $37^{\circ} \mathrm{C}$ and placed on a standard and a heated plate.

On a standard plate the fibrinolytic activity of the fractions showed following distribution; there were two kinds of peaks of streptokinase-activated lysis(12), one was distributed between fraction number 5 to 7 , and another was found between 8 to 19 . On a heated plate the fibrinolytic activity appeared from fraction number 9 to 15 . Both plasminogen and proactivator, contained in the effluent, were considered as a source of fibrinolytic activity. 
Case 1. Diagnosis: Urticaria acuta

A 28-year-old male developed pruritic urticarial lesion all over the body. Blood examination, carried out prior to treatment, showed acceleration of fibrinolytic activity (streptokinase-activated lysis) as shown in Fig. 2. Marked fibrino-

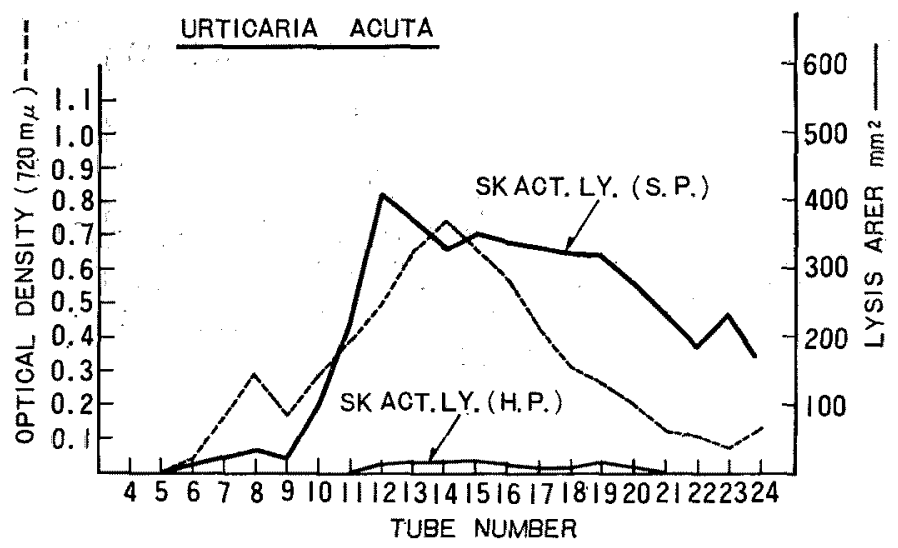

Fig. 2

lytic activity was found from fraction number 14 to 24 on a standard plate. By comparing protein concentration of each fractions with fibrinolytic activity of them the difference between normal and some pathologic condition would become distinct. No remarkable change was seen in the fibrinolytic activity (streptokinase-activated lysis) on a heated plate.

The existence of intensified blood fibrinolytic activity in case of urticaria was already known (1). The results of the experiment clarified that the substance of fibrinolytic enzyme system, which showed increased streptokinase-activated lysis on a standard plate, was one of the sources of the activity. Proactivator should be considered as the substance.

Case 2. Diagnosis: Fibrinolytic purpura

A 53-year-old male developed repeatedly a few purpuric lesion of extremities of several weeks' duration. Marked hypofibrinogenemia $(60 \mathrm{mg} / \mathrm{dl}$ ) was noted by routine examination. The untreated serum of the patient itself showed conspicuous fibrinolytic activity on a standard plate, and the activity was inhibited by adding epsilon-amino-n-caproic acid(1) in the plate. The activity of the untreated serum, however, disappeared after keeping 24 hours at $0^{\circ} \mathrm{C}$ and also treating with Sephadex G-200. The fibrinolytic activity (streptokinase-activated lysis) on a standard plate and the protein concentration were shown in Fig. 3. Proactivator, found in the earlier fractions and also in the later fractions, 


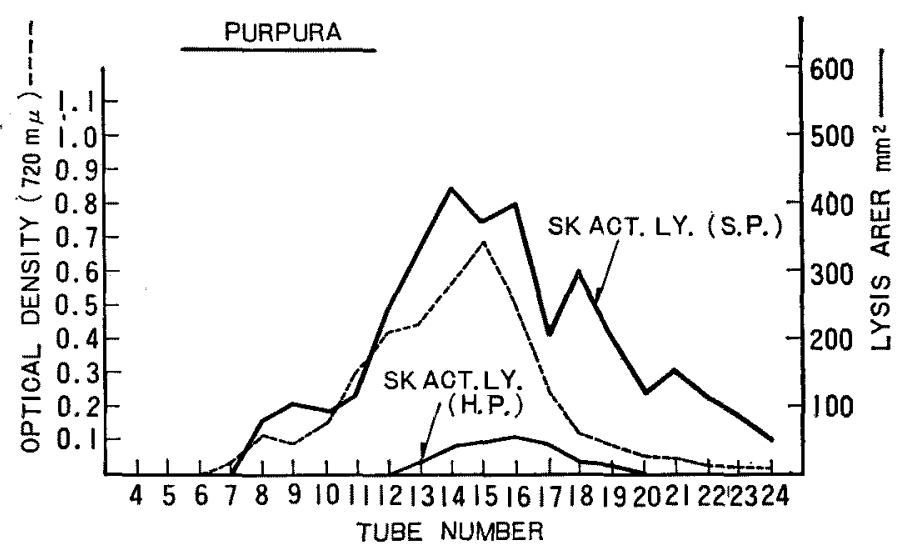

Fig. 3

revealed marked fibrinolytic activity.

Case 3. Diagnosis: Pemphigus vulgaris

A 23-year-old female developed recalcitrant bullous lesions all over the body. Citrated plasma was fractionated with same method in this case. The results were shown in Fig. 4. Very distinct increase in the fibrinolytic activity (strepto-

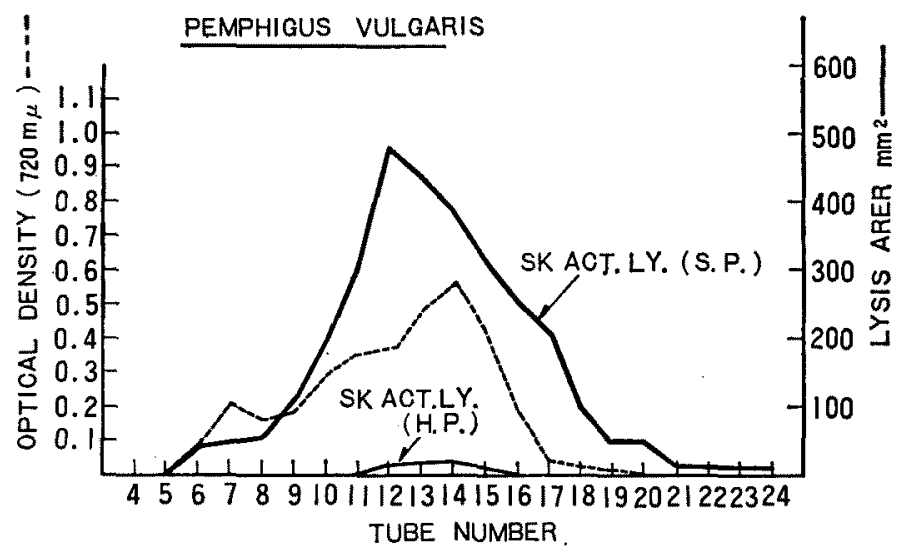

Fig. 4

kinase-activated lysis) on a standard plate was found from fraction number 11 to 17. Though the cause of pemphigus has not been clarified, this pathological fibrinolytic activity due to proactivator seemed to suggest the changes of fibrinolytic enzyme system in case of the disease. 


\section{SUMMARY}

New method for determination of blood fibrinolytic activity of patient with skin disease by means of gel filtration was discussed.

Each one case of urticaria acuta, fibrinolytic purpura and pemphigus vulgaris showed marked fibrinolytic activity (streptokinase-activated lysis) on a standard plate. The results of the experiments suggested that proactivator should be given much attention in some dermatoses.

Parts of this paper have been presented at the 14th Annual Congress of The Japanese Society of Allergy on Nov., 20, 1964 in Nagoya. The assistance of the staff of Department of Physiology, School of Medicine, Keio University, is gratefully acknowledged.

\section{REFERENCES}

1. Yokoyama, K. \& Hatano, H.: Keio J. Med., 8: 303, 1959.

2. Hatano, H. et al.: ibid., 11: 127, 1962.

3. Hatano, H. et al.: ibid., 11: 167, 1962.

4. Hatano, H. \& Yamamoto, K.: ibid., 12: 113, 1963.

5. Hatano, H. et al.: Jap. J. Dermat. Ser. B., 73: 120, 1963.

6. Robbins, K. C. \& Summaria, L.: J. Biol. Chem., 238: 952, 1963.

7. Cohly, M. A., \& Shulman, S.: Biochim. Biophys. Acta, 73: 293, 1963.

8. Berg, W. \& Korsan-Bengtsen, K.: Thromb. Diath. Haemorr., 9: 151, 1963.

9. Lewis, J. H.: Proc. Soc. Exp. Biol. Med., 116: 120,1964.

10. Flodin, P. \& Killander, J.: Biochim. Biophys. Acta, 63: 403, 1962.

11. Lowry, O. H. et al.: J. Biol. Chem., 193: 265, 1951.

12. Takada, A. et al.: Keio J. Med., 13: 187, 1964. 